\title{
An initiative to teach family systems nursing using online health-promoting conversations: A multi-methods evaluation
}

\author{
Lindh R. Viveca ${ }^{1}$, Persson V. Chatrin ${ }^{1}$, Saveman Britt I nger ${ }^{1}$, Englund Claire $\mathrm{J}^{2}$, I dberger Karl ${ }^{2}$, \\ Östlund E.A. Ulrika ${ }^{1}$
}

1. Department of Nursing, Umeå University, Sweden. 2. Centre for Teaching and Learning, Umeå University, Sweden.

Correspondence: Lindh R. Viveca. Address: Department of Nursing, Umea University, S-90187 Umea SWEDEN. Telephone: 46-907-869-262. Fax: 46-907-869-169. Email: viveca.lindh@nurs.umu.se.

Received: J une 12, 2012

DOI : $10.5430 /$ jnep.v3n2p54
Accepted: July 17, $2012 \quad$ Published: February 1, 2013

URL: http://dx.doi.org/10.5430/jnep.v3n2p54

\section{Abstract}

Background: Family systems nursing embraces the view that one family member's illness affects other family members and vice versa. Family nursing developed as a way for nurses to work with families to promote health. Previously, teachers performed most of the education on health-promoting conversations with families on campus. Because online education is increasingly requested in nursing, this article evaluates teaching family systems nursing by using synchronous online health-promoting conversations.

Methods: Fifteen registered nurses attended the course "Health-Promoting Family Focused Nursing", an advanced-level nursing elective 10-week course. The course used technology enhanced learning and was evaluated qualitatively and quantitatively. Students and teachers participated in semi-structured focus group interviews analyzed qualitatively. The students filled in a traditional course evaluation. Students responded before and after the course to the multidimensional research instrument “Families’ Importance in Nursing Care-Nurse’s Attitudes” (FINC-NA).

Results: The students were satisfied with the course and the synchronous health-promoting conversations. They learned to "think family" and acknowledged the importance of inviting families to take part in the care of a family member. They stated that the online practice had helped them gain a useful tool for their future family nursing practice. The teachers appreciated working in a team to develop the course. At the start of the project they viewed the online technology as a challenge. However, during the course they saw many pedagogical possibilities with the synchronous meetings and that the online family conversation training worked well. The ability to record the meetings offered educational advantages and the opportunity for students to reflect on the conversations. Even if the students rated families importance in nursing care positively prior to the course on FINC-NA, the students still gave the following domains even stronger support post-course: Family as a resource in nursing care, Family as a burden, and Family as own resource.

Conclusions: Family systems nursing and health-promoting conversations with families, comprising interaction between several participants, can be learned using online pedagogical methods. Furthermore, the belief that health-promoting family conversations need to be held with all participants in the same room has been challenged. 


\section{Key words}

Family nursing, Health-promoting conversations, Education, Technology enhanced learning, Blended learning

\section{I ntroduction}

From a systemic view it is obvious that an illness held by one family member effects all other family members and vice-versa ${ }^{[1,2]}$. Family nursing developed as a way of working with and thinking about families, and effects how nurses interact and communicate with patients and families ${ }^{[2,3]}$. Traditionally the practice of nursing concentrates on individual patients ${ }^{[3]}$ and nurses may need to modify their usual pattern of clinical practice to adopt a family nursing approach ${ }^{[2]}$. For such a shift nurses need new theoretical knowledge and clinical skills ${ }^{[2-5]}$. Nurses can gain these new skills by combining their personal experience with family nursing theory and by using examples from their clinical training, past experience, and skills ${ }^{[3]}$.

In 1998, a Family Care Unit was established at Kalmar University (today Linnaeus University) in Sweden. An intervention, "health-promoting family conversations" developed to help families experiencing illnesses to create or begin to create new beliefs, new ideas, meanings, and possibilities in relation to a problem ${ }^{[6]}$. This intervention was influenced by the work of Wright and Leahey at the University of Calgary in Canada ${ }^{[7]}$. Previous clinical and research experiences show that a series of three conversations usually is enough for most families ${ }^{[8]}$. The conversations are led by two nurses. One nurse takes primary responsibility for the conversation and the other is a co-participator in the conversation, e.g. an observer of meta-communication ${ }^{[1]}$. The three conversation sessions focus on topics that the families consider important and the dialogue attempts to identify and release resources in and around the family. During the conversations all family members are invited to tell their story and to listen to each other's stories. To create alternative ways for families to think about their situation, reflecting questions are offered ${ }^{[1,7]}$. Two or three weeks after the last conversation, "a closing letter" is sent to the family (c.f. therapeutic letters) ${ }^{[9]}$. In the letter the nurses offer their reflections on what happened during the conversations and the family resources are highlighted.

Over the past 15 years, beginning with Kalmar University, students have been educated on family-focused nursing through courses at undergraduate and graduate levels ${ }^{[10]}$. At the Department of Nursing, Umeå University, a family focused education and research milieu was established and courses are in development. Umeå is located in northern Sweden. The geography forces students to travel long distances stimulating the development of online education. Within the nursing field, this affects the advanced levels more severely. Because advanced level nursing education addresses students already working as nurses, and those students often have young children, there is a need for flexible academic learning opportunities that are not geographically limiting.

The use of Information and Communication Technology (ICT) in higher education has grown rapidly since the 1990s and is now a fundamental part of the student learning experience for students studying both at a distance and on campus ${ }^{[11]}$. A recent survey revealed that nearly one-third of all students in higher education in the United States are taking at least one online course ${ }^{[12]}$. An even greater increase has taken place at Umeå University, Sweden where the proportion of students studying online or taking blended courses has increased from $38 \%$ to $73 \%$ over the last five years. However, online education for professional education such as nursing still needs to widen opportunities and facilitate 'on demand' education to suit individual nursing student needs ${ }^{[13]}$. Understanding how nursing students around the world are educated with regard to family nursing theory, research, and practice in graduate and undergraduate programs is also essential ${ }^{[14]}$. Several questions about the pedagogy used when teaching family nursing might be raised to learn how a student best learns about caring for families experiencing illness ${ }^{[15]}$. Despite the increased interest in family nursing education and technology enhanced learning (TEL), there is a lack of documentation sharing and evaluating strategies for online teaching in the field ${ }^{[16]}$ and very little research into the use of synchronous online environments in general ${ }^{[17]}$. 
This study evaluates an initiative for online teaching of health-promoting family conversations using an online environment. Specific research questions were: 1) Is it possible to teach family systems nursing using online teaching methods? 2) Can health-promoting conversation be conducted in an online environment? 3) Can the knowledge necessary to carry out health-promoting conversation be acquired in an online environment?

\section{Methods}

The study used a research design with both quantitative and qualitative components allowing multiple perspectives to be evaluated.

\subsection{The course}

The course "Health-Promoting Family Focused Nursing" was an advanced-level nursing elective 10-week course. The proposed learning outcomes focused on skill development and knowledge for planning and conducting health-promoting conversations with families as described by Benzein, Hagberg, and Saveman ${ }^{[1]}$. This particular course was part of a project aiming at development of online environments in teaching at the university. The course was published using a learning management system (LMS), Cambro ${ }^{[18]}$. This is an open source system supporting technology with enhanced teaching, learning, and collaboration available to all employees and students at the university ${ }^{[19]}$. The web conference solution Adobe ${ }^{\circledR}$ Connect ${ }^{\mathrm{TM}}$ (AC) ${ }^{[20]}$, a system provided free of charge by the Swedish University Computer Network (SUNET), was used for online conversations. Adobe Connect is a web conferencing tool that runs through a web browser using a flash plug in. Adobe Connect enables collaboration with live sound and video, similar to Skype but with more powerful collaboration tools, i.e. document-and desktop sharing and the ability to record meetings. It is also possible to apply different roles to the participants and to play back video and sound clips. No download or installation is needed and each participant can connect to the meeting using their own personal computer, Web camera, Internet connection and headset.

To introduce the course, students and teachers met once on campus for information, lectures on family systems nursing, health-promoting conversations and system theory, and an evening "get together" to get to know each other. During the on-campus introduction to the course students received an interactive introduction to AC. This introduction consisted of basic equipment requirements and principles for the implementation of meetings in AC. The lecture placed extra emphasis on self-help, information centers, support, guides, and instructions. A collective online introduction to AC followed a few days later. As a complement to the course literature on family system nursing theory, Dr. L. Wright from Calgary Canada held two online lectures using AC to support the students' learning.

Interaction between several participants in the online conversation via AC was an essential part of the course. For the purpose of cooperation between students, and to facilitate student active learning in which an individual contribution to collective problem-solving and reflection is essential ${ }^{[21]}$, students were divided into study groups (7-9 students per group). Family role plays via AC were used to train skills in health-promoting conversations ${ }^{[9]}$. For the family role-plays each study group was divided into three conversational groups (3 students per group). Each conversational group designed "a family" for one other group to act on.

The first of three conversations was held on campus and video-recorded. The next two conversations were performed online in AC with the participants geographically spread. The teachers recorded the conversations in AC and published them on the LMS, Cambro. Each role-play in AC was performed as follows: The "nurses", one of whom led the conversation, took part in the health- promoting conversation with "the family." At the end of the conversation the nurses offered the family the opportunity to listen to their reflections on what had been said. Then the other students in the study group acted as a reflecting team and gave their thoughts on what they heard and offered commendations and options to the "family." Finally the "nurses" asked the "family" to give their thoughts on the reflections. After the session the students abandoned their roles and the students and teachers discussed the session. 
Individually, the students then watched the recorded conversations and provided written assignments based on family system nursing theory ${ }^{[1,2,22]}$. Each study group performed a scheduled synchronous AC session after each online conversation where the students were asked to share their reflections on each other's assignments. The teachers assessed and graded the students' achieved skills during the third conversation session. The students wrote a theory-based review paper on the subject demonstrating their theoretical knowledge in family system nursing.

\subsection{Participants}

Seventeen registered nurses (RNs), including two male nurses, started the course and 15completed it. The participating RN's median age was 41 years (range 28-59) and the median time working as an RN was 13.5 years (range 3-27). Two RNs worked in pediatrics/neonatal care, two with surgical/orthopedic care, three in internal medicine, four in emergency/intensive care, and finally three in psychiatric or psycho-geriatric care. At the baseline, 10 of the participants were family members to someone who had suffered from severe illness and needed professional care. At follow up, this number raised to 12. Students' earlier experiences of using AC and Cambro were good; only two students reported no experience using either AC or Cambro. All participants were advanced level students participating in a specialist-nursing program.

The four teachers from the Department of Nursing participating in the pre-course and post-course interviews were female and aged 58-61. Teaching experience ranged from midwifery, pediatric nursing, and district nursing to acute care nursing. Three of the teachers were experienced in TEL. Academic experiences included two lecturers with master's degrees, two doctors (one an assistant professor and one full professor.)

\section{Data collection and analysis}

\subsection{Students' perspectives}

A post-course evaluation form was distributed including 20 Likert response questions covering issues on student satisfaction with the course outline, teaching, literature, examination, and technique. Additionally, two open questions on what they had learned, and suggestions on how to improve the course was administered to the students. A semi-structured focus group interview ${ }^{[23]}$ was conducted on how the online learning environment worked, whether the students would have taken the course if offered on campus, and the benefits and opportunities for course improvement. The interview was tape recorded and transcribed verbatim before analysis. Because of difficulty finding a suitable time, only two students participated in the focus group.

The quantitative responses were analyzed using descriptive statistics ${ }^{[23]}$ and the outcomes dichotomized in positive and negative responses. Qualitative data from the open-ended questions and the focus group interview transcript were read through several times and text units labeled to describe their content, then synthesized in categories by searching for similarities and differences across questions and interview text ${ }^{[24]}$.

Before and after the course, the attending RNs answered the multidimensional research instrument "Families' Importance in Nursing Care-Nurses' Attitudes" (FINC-NA). FINC-NA is a 26-item instrument developed in Sweden ${ }^{\text {[25] }}$. The response format is of numeric type ranging from $1=$ strongly disagree to $5=$ strongly agree. FINC-NA measures attitudes on the following four dimensions: Family as a resource in nursing care (Fam-RNC); Family as a conversational partner (Fam-CP); Family as a burden (Fam-B) and; Family as its own resource (Fam-OR) ${ }^{[25,26]}$. FINC-NA has recently been psychometrically refined and revalidated. The dimensionality was reproduced, internal consistency for the total scale, Fam-RNC and Fam-CP subscales showed alpha $>0.80$. None of the scales showed alpha below 0.70. All scales demonstrated satisfactory test-retest reliability evaluated with intraclass correlations: FINC-NA total scale (0.89), Fam-B (0.86), Fam-OR (0.80), Fam-RNC (0.79), and Fam-CP $(0.71)^{[26]}$. The data was analyzed by using the Statistical Package 
for the Social Sciences (SPSS) versions $18.0^{[27]}$. Given the small number of participants and potential for non-normal distribution, data from FINC-NA were analyzed as single items and the Wilcoxon signed rank test ${ }^{[23]}$ was used to compare pre-course and post-course data. The significant level was set at $p<.05$ for all comparisons.

\subsection{Teachers' perspectives}

Semi-structured focus group interviews were carried out with the four teachers involved in the project prior to and post course implementation. All interviews were tape recorded and transcribed verbatim. An inductive thematic analysis approach was used to analyze the interviews by thorough reading and rereading of the interview transcripts, noting emerging themes and concepts, contradictions, and problem areas to be synthesized into categories ${ }^{[24]}$.

\section{Results}

\subsection{Students' perspectives}

Based on the quantitative part of the course evaluation, all students were satisfied with the course, rating the overall quality of the course and the response they received as students during the course highly. They all expressed that the collaboration between teachers and students had been good during the course and that they had contributed actively to the positive progression of the course. All students thought that the pedagogical approach encouraged them to think critically and constructively, and that lectures and seminars were valuable for them. Most of the students rated the examinations as providing an opportunity to demonstrate their knowledge. A majority of the students agreed they were given adequate feedback on their assignments. Additionally, the majority of students agreed that the online learning environment, AC and Cambro, functioned well.

Six categories were abstracted from responses on the open-ended questions in the qualitative part of the course-evaluation and from the focus group interview.

\section{Relevant training on how to communicate/ talk with families}

This category embraced the students' positive experience of the pedagogical approach, including relevant training in using specific open and circular questions and the chance to talk with families. Reflecting on the conversations with families fostered support for future care activities involving families.

"We have been drilled in using the different kinds of questions to be used, and the best learning activities must be to be able to practice as we have done."

The students highlighted that some nonverbal communication was lost during the online communication but they could still see facial expressions, which were considered important. Practicing communication online and recording the conversations was a positive experience.

\section{Technical and learning support}

The technical support provided at the beginning of and during the course was very much appreciated and "made things easier." In regard to the learning support from lecturers, the students asked for quicker responses "...it should not take days to get a response on messages sent." Furthermore, it was suggested that the lecturers give more feedback on the assignments to support the students' learning. The students also greatly appreciated the two oral lectures by Dr. Wright from Canada. 


\section{The technology}

The technology with AC worked better than students expected but a few ongoing problems arose. All of the technical problems described were related to the live lectures streamed from Canada. One of the lectures took too long to start and there were sound delays. The students suggested recording the lectures and making it possible to send questions through e-mail within a fixed time period.

\section{Suggestions on how to improve study assignments}

Students expressed that there were too many written reflective assignments and that the topic of the final theoretical paper should be changed, i.e. not having a similar focus to the preceding assignments. A suggested topic for the final paper was "writing a closing letter" as a natural part of the course to practice writing a letter to the family.

"It would have been more rewarding to write a closing letter to the family we had talked to in the conversation group ..."

\section{I nstrumental knowledge on working with families}

This category was expressed as a new way of thinking to involve the family in patient care and alternative ways to see and acknowledge all family members. Students considered the use of circular questions to be a useful learning experience in many ways. Students also expressed that they had started using family systems nursing theories and models in their clinical work.

"We have learned valuable tools to be implemented in our professional practice, in such situations where family conversations are possible to use."

The students highlighted the focus on family strengths and resources and the importance of the nurse's role in helping patients and families. The main message of the course was described as, "conversing in a way that the family was able to work with themselves.” Such a process may lead to a realization of how families can change their situations.

"I have learned what small measures can be used as an effective way to support a family in changing their perspective and to challenge their constraining beliefs."

\section{A change toward more positive attitudes in relation to family involvement}

This category included a change in attitude toward families and approaching families. Families were seen as great resources and not as burdens. The importance of including families in the patient care was highlighted because "everybody is affected." It was learned that families could always be more or less involved depending on the level of care. If there is not time for conducting health-promoting conversations, showing a genuine interest in families is still of significant importance.

"An important learning experience is that a family is a unit and that it is always worthwhile inviting them to participate in conversations."

Participating in the course gave the students a new perspective and instead of "thinking of a patient, they learned to think family."

Finally, changes in nurses' attitudes in regard to families' importance in care measured with FINC-NA showed significant attitude improvements in five of ten items on the Fam-RNC scale. The Fam- CP scale showed no significant results. On the Fam-B scale, two of four items showed significant improvement, and on the Fam-OR scale three of the four items were significantly improved, see Table 1. 
Table 1. Pre-course and post-course comparisons on nurses' attitudes in regard to families' importance in care

\begin{tabular}{|c|c|c|c|}
\hline Scales and Items of the FINC-NA & $\begin{array}{l}\text { Pre-course } \\
\text { Median } \\
\text { (Range) }\end{array}$ & $\begin{array}{l}\text { Post-course } \\
\text { Median } \\
\text { (Range) }\end{array}$ & $\mathbf{P}^{\#}$ \\
\hline \multicolumn{4}{|l|}{ Family as a resource in nursing care (Fam-RNC) } \\
\hline The presence of family members eases my workload & $3.0(1-5)$ & $4.0(3-5)$ & $0.021 *$ \\
\hline The presence of family members gives me a feeling of security & $3.0(3-5)$ & $4.0(3-5)$ & $0.038 *$ \\
\hline The presence of family members is important to me as a nurse & $4.0(4-5)$ & $5.0(4-5)$ & 0.059 \\
\hline Family members should be invited to actively take part in the patient's nursing care & $4.0(3-5)$ & $4.5(3-5)$ & 0.130 \\
\hline Family members should be invited to actively take part in planning patient care & $4.0(1-5)$ & $5.0(3-5)$ & 0.161 \\
\hline A good relationship with family members gives me job satisfaction & $4.0(4-5)$ & $5.0(5-5)$ & $0.005^{*}$ \\
\hline Getting involved with families gives me a feeling of being useful & $4.0(2-5)$ & $5.0(4-5)$ & $0.011 *$ \\
\hline I gain a lot of worthwhile knowledge from families which I can use in my work & $5.0(3-5)$ & $5.0(4-5)$ & 0.480 \\
\hline The presence of family members is important for the family members themselves & $4.5(4-5)$ & $5.0(3-5)$ & 0.739 \\
\hline It is important to spend time with families & $5.0(3-5)$ & $5.0(5-5)$ & $0.023 *$ \\
\hline \multicolumn{4}{|l|}{ Family as a conversational partner (Fam-CP) } \\
\hline I invite family members to have a conversation at the end of the care period & $3.0(1-5)$ & $3.5(2-5)$ & 0.191 \\
\hline $\begin{array}{l}\text { I ask family members to take part in discussions from the very first contact, when a } \\
\text { patient comes into my care }\end{array}$ & $3.0(2-5)$ & $4.0(2-5)$ & 0.132 \\
\hline I always find out what family members a patient has & $4.0(2-5)$ & $4.0(2-5)$ & 0.257 \\
\hline I invite family members to speak about changes in the patient's condition & $4.0(3-5)$ & $5.0(3-5)$ & 0.058 \\
\hline I invite family members to speak when planning care & $5.0(3-5)$ & $5.0(2-5)$ & 0.564 \\
\hline It is important to find out what family members a patient has & $5.0(4-5)$ & $5.0(4-5)$ & 0.317 \\
\hline I invite family members to actively take part in the patient’s care & $4.0(1-5)$ & $4.0(2-5)$ & 0.248 \\
\hline $\begin{array}{l}\text { Discussion with family members during first care contact saves time in my future } \\
\text { work }\end{array}$ & $4.0(2-5)$ & $5.0(3-5)$ & 0.084 \\
\hline \multicolumn{4}{|l|}{ Family as a burden (Fam-B) } \\
\hline The presence of family members makes me feel that they are checking up on me & $2.0(1-2)$ & $2.0(1-4)$ & 0.832 \\
\hline The presence of family members makes me feel stressed & $2.0(1-4)$ & $1.0(1-4)$ & $0.035 *$ \\
\hline The presence of family members holds me back in my work & $2.5(1-4)$ & $2.0(1-2)$ & $0.021 *$ \\
\hline I don’t have time to take care of families & $2.0(1-4)$ & $2.0(1-3)$ & 0.527 \\
\hline \multicolumn{4}{|l|}{ Family as own resource (Fam-OR) } \\
\hline $\begin{array}{l}\text { I encourage families to use their own resources so that they have the optimal } \\
\text { possibilities to cope with situations by themselves }\end{array}$ & $3.5(2-5)$ & $4.0(3-5)$ & $0.033^{*}$ \\
\hline $\begin{array}{l}\text { I see myself as a resource for families so that they can cope as well as possible with } \\
\text { their situation }\end{array}$ & $3.5(2-5)$ & $4.0(2-5)$ & 0.218 \\
\hline I consider family members as co-operating partners & $4.0(1-5)$ & $5.0(3-5)$ & $0.026 *$ \\
\hline I ask families how I can support them & $3.0(2-5)$ & $4.0(3-5)$ & $0.021 *$ \\
\hline
\end{tabular}

\#Wilcoxon Signed Rank Test, 2-tailed

${ }^{*} p<0.05$ is considered significant

\subsection{Teachers' perspectives}

From the pre-course and post-course interviews with teachers the following five categories were abstracted: teamwork, expectations concerning technology, expectations concerning pedagogy, technology - pedagogical possibilities and challenges, and dissemination plans and pedagogical merits.

\section{Teamwork}

The teachers expressed that because the course was developed within a project, they could spend additional time on development and teaching, making it possible to work as a team. This was considered as highly positive in both the preand post-course interviews. 
"It's an asset that we can work as a team and support each other. It's much more enjoyable in contrast to other courses where you are a single teacher and have no one to discuss the course with."

\section{Expectations concerning technology}

Pre-course, the teachers expressed apprehension in regard to the AC technology. Based on previous experiences with AC in teaching the teachers doubted the stability and reliability of the system.

"I don't think the technology is really stable. I want to feel that if we have created a course where dialogue is central, then it must be like driving a Volvo. It must work, be user friendly, and be foolproof."

The teachers also emphasized the importance of technology that allows teachers and students to work freely. Pre-course, the group stressed the need for good technical support and a thorough introduction for both teachers and students. The importance of good technical support was again mentioned in the post-course interview.

"It's training (in the technology) that makes you feel safe and secure when using it, both for us and the students."

The students' technical competence and the quality of their computer hardware were also a source of pre-course concern. However, the teachers' previous experience was that technical problems are rarely a cause of dropout among students. With clear instructions many problems can be avoided. Because most of the teachers involved had extensive experience with AC and teaching online it was considered an advantage, providing them with a sense of security in their own ability to deal with technical problems and giving a realistic view of what could be achieved using the available technology. Prior to the course, the teachers were doubtful that carrying out health-promoting conversations with families in AC would be successful. The lack of eye contact and physical presence was cause for concern.

\section{Expectations concerning pedagogy}

Pre-course, the teachers saw the implementation of the course as a pedagogical challenge, but a positive one:

"It's clear that it's a pedagogical challenge, but it's also fun and of course we're going to test this way of working."

Pre-course, the general opinion of the teachers was that using AC to facilitate online conversations is an exciting pedagogical possibility not too different from teaching in the classroom. In general, the teachers were more confident with regard to their pedagogical methods, and thought that the course had good structure and content.

\section{Technology - pedagogical possibilities and challenges}

Post-course, all of the teachers agreed that the medium did favor a reflective style of working because it required participants to listen carefully to the conversation and excluded the usual distractions of the classroom.

"There were some conversations that I perceived as slow, but the family involved didn't experience them as such. On the contrary, the participants explained that it gave them time to reflect. Holding the conversation in AC gave more time for reflection than when everyone is in the same room."

The teachers' pre-course fears that the encounters online would not be good enough to catch, for example eye-contact, were not realized. Although facial expression and eye-contact were not always easy to achieve using AC, the teachers concluded post-course that the need to concentrate on verbal information took precedence. 
Although the technology functioned better than expected, post-course the teachers were unanimous in their view that they could not always rely on it to work. When working with the students in AC, frequent shifts in focus between the course content and the technology used was a challenge for the teachers. Students were required to use their own computers with adequate processing power to operate the AC program and learn the support system. The ability to record conversations was invaluable for the students in that it enabled them to view conversations at a later date, reflect on their participation, and follow their development over time.

\section{Dissemination plans and pedagogical merits}

The teachers were positive post-course to carrying out the course again using AC for health-promoting family conversations in the future and also expressed the opinion that an international online course would be beneficial. They explored many possibilities for the future, e.g. the use of new technologies and virtual worlds to create a family care center. The technology and educational processes explored in this project, such as carrying out and recording online communication also can be implemented in other courses. The teachers also acknowledged that publishing results and using the experience gained in the project to demonstrate expertise was something that could be included in their pedagogical merit portfolios.

\section{Discussion}

The present study is, to our knowledge, the first description of a course outline where the health-promoting conversations are performed online in a blended learning environment. The principle findings were that the students learned how to interact with families using online training methods. The use of synchronous online meetings worked better than anticipated by both teachers and students. Most of the work on family nursing education in academia has been accomplished in Canada and the United States. However, there is a growing body of family nursing curriculum and teaching initiatives from other countries as well, such as in Sweden ${ }^{[14]}$. The courses are usually designed as campus courses but also offered as blended learning ${ }^{[16]}$. The training in health-promoting conversations is usually performed on campus in special labs with video recording equipment available ${ }^{[28]}$. This makes the present study of the initiative to teach family systems nursing using online health-promoting conversations unique.

The students evaluated the course positively. They had learned alternative ways to see and acknowledge all family members and to involve the family in patient care. Students had started using family systems nursing theories and models in their clinical work and they had learned to "think family". The frequent opportunities for synchronous interaction between students and student-teachers on AC might have contributed to the positive student evaluations. On the other hand, students desired more feedback on assignments and quicker answers to e-mails. This is in accordance with Gaudine and Moralejo ${ }^{[29]}$ showing that students value frequent feedback and interaction with their teachers. The students expected the course to use blended learning and this was preferable to them in contrast to a campus course. This might be another reason for positive evaluations because travel to the campus was minimal. Student active learning in online environments with peer interaction and access to experienced teachers makes blended learning advantageous for graduate nursing students living geographically spread ${ }^{[30]}$.

Swedish RNs have a supportive attitude regarding the importance of involving families in nursing care when measured by FINC-NA ${ }^{[31]}$. In our study, when looking at FINC-NA median scores at course introduction, the students rated family involvement even more important than RNs in that study ${ }^{[31]}$. FINC-NA has previously shown to have problems with ceiling effects ${ }^{[26]}$.That item scores pre-course reached toward the upper levels of the scales could have affected the possibilities to demonstrate significant changes post-course ${ }^{[32]}$. Even so, statistically significant changes were found in half of the items on the attitude dimension "Family as a resource in nursing care" (Fam-RNC) and the dimension "Family as a burden" (Fam-B). One of the items showing significant improvement ("It is important to spend time with families", (Fam RNC) demonstrated the highest possible median score both pre- and post-course telling us that the ceiling effects is only on possible explanation for non-significant results. 
In regard to the FINC-NA dimension "Family as a conversational partner" (Fam-CP) no changes were evident in any of the items. Even if these items do reflect attitudes about the importance of involving families in nursing care, they ask for nurse activities conducted to involve families in the care. We argue that for nurses to work in such a way, not only is a change in attitude crucial but also a care context supporting such a task. This may also explain the lack of significant improvement in attitudes on activities such as inviting family members to actively take part in the patient's nursing care and for nurses to plan the patient's care together with the family (Fam-RNC) and in nurses rating not having time to take care of families (Fam-B). Finally, in regard to the dimension "family as its own resource” (Fam-OR), all items except one showed improvements. In the qualitative findings the students stated that prior to course end they had already changed their attitudes toward seeing the family as a unit and the importance of including families in patient care.

Collectively, the student reviews post-course indicate a more positive outlook and more supportive attitude toward family involvement than pre-course. Traditionally nursing tasks are, at best, offered within a person- centered atmosphere ${ }^{[33]}$. The implementation of the family systems nursing concept in nursing practice needs a nursing leadership with ambitions for implementing the concept in health care organizations ${ }^{[34,35]}$. Fostering positive attitudes in advanced level RN students toward families' importance in nursing care may facilitate the development of such leaders.

When planning the course the teachers feared the technology may not be stable or user friendly but experienced it functioned better than expected. Also the students thought that the technology including the online learning environment AC functioned well and that the pedagogical approach encouraged them to think critically and constructively. The teachers highlighted the ability to record and view conversations at a later date as a pedagogical possibility and students expressed the view that reflecting on the conversations with families fostered support for future care activities involving families. Teachers experienced using AC favored a reflective style because participants had to listen carefully to the conversation and it excluded the usual distractions of the classroom.

The drawback or disadvantage with AC and similar tools is that body gestures, facial expressions and tone of voice, are sometimes hard to see or recognize through a web interface. The sound and video quality can be of varying quality due to lack of required equipment, moderate user experience or more seldom, network problem on the Internet. In an optimal setting, with a good camera and headset, the quality of the meeting is equal to face-to-face interaction. The teachers' fears that carrying out health-promoting conversations with families online using AC would not be good enough to pick up non-verbal clues such as eye contact were not realized. Although facial expression and eye-contact were not always easy to achieve, a focus on verbal information took precedence. The students experienced that some nonverbal communication was missed but that they could still see face expressions and were positive to the ability to practice communication online.

Prior to the course, the teachers expressed anxiety and misgivings regarding the technology, however post-course topics mainly concerned the pedagogy, e.g. abilities to reflect and how this may influence student learning and methods of examination. This reflects a natural progression from technical mastery to pedagogical development for the teachers ${ }^{[36]}$. The teachers were first worried about the technology but then became more secure and dared to push their limits and see the possibilities offered by online education, e.g., using lecturers who were geographically distant and recordings for reflection. The present course became an example of education-driven development in which the teachers discussed emerging pedagogical ideas within a technological environment. TEL should be education-driven in order to fit into efforts of pedagogical development - not the other way around ${ }^{[37]}$.

In this course, reflection as a pedagogical method was used throughout as a way to transform experiences using narrative interactions to learn new ways of thinking and acting. Reflection is extensively used in nursing education ${ }^{[38]}$. This might also have helped the students' following their own learning progress ${ }^{[39]}$. Reflection is also a central component of the health-promoting conversations ${ }^{[1,40,41]}$ making practicing reflection crucial. The use of reflection online via AC was occasionally slow, but not detrimental, as this gave the students time for individual reflections as an "inner dialogue" ${ }^{[42]}$. 
All assignments were based on reflective discussions or reflective writing on the health-promoting conversations and the theoretical ground behind the practice. The students found this a bit repetitive and suggested that the final theoretical assignment instead included writing a closing letter, also called a therapeutic letter ${ }^{[9,43]}$ to their fictive families. On the other hand, students commented that the reflections supported their knowledge and performance of health-promoting family conversations. They were drilled in their skills to pose circular questions and found they had learned a technique to challenge families' constraining beliefs "with small measures” ${ }^{[44]}$. The process of knowledge exchange between science and clinical practice of family systems nursing requires diligence ${ }^{[45]}$. How these students will manage to use their skills in clinical practice would make room for another interesting study.

The development of the course was, first and foremost, for educational purposes but it was also developed with the intention of exploring the opportunities offered by e-health and a possible application of online and blended learning in a clinical context, especially in remote and rural nursing ${ }^{[46]}$. Today there is a rich body of research on internet supported interventions using a variety of web-technologies. However, to our knowledge, there are hitherto no studies on synchronous e-meeting-based group interventions with several participants interacting with each other in the session ${ }^{[47]}$. The positive outcome of the course is encouraging for work with health-promoting family conversations in clinical settings and for online learning.

The relatively few students participating in the course and the absence of a control group, who could perform all three conversations on campus, limited the study. The project group did not consider the design with a control group participating in a campus course because it was impossible for some students to travel to the campus. However, a design with both quantitative and qualitative components allowed multiple perspectives to be evaluated.

The results of this study encourage the use of on-line health-promoting family conversations in clinical practice. Further research would evaluate the clinical use of on-line health-promoting family conversations in remote and rural nursing. For pedagogical purposes new technologies such as virtual reality worlds to create a family care center would be tested.

\section{Conclusion}

With this course outline we have shown that family systems nursing can be taught using online teaching methods, providing theoretical knowledge and fostering a supportive attitude toward family involvement. The students were shown to have gained the clinical skills necessary to work with families and conduct health-promoting conversations demonstrating that health-promoting conversations with families, comprising interaction between several participants, can be learned and conducted using an online environment. Furthermore, the belief that health-promoting family conversations need to be accomplished with all participants in the same room has been challenged. By working with the course, the teachers were able to gain experience of new pedagogical possibilities offered by online education and their apprehension regarding the technology was challenged. Technology enhanced education has many advantages to offer learners and teachers, such as flexibility and new pedagogical opportunities, and can be used to attract both national and international nursing students to nursing education.

\section{Acknowledgement}

We are grateful to the participating students for taking their time to give their views on the course and to lecturer Lisbeth Sjöström for her contribution to the course development. We also thank Umeå University for financial support.

\section{References}

[1] Benzein EG, Hagberg M, Saveman BI. 'Being appropriately unusual': a challenge for nurses in health-promoting conversations with families. Nurs Inq. 2008; 15: 106-115. PMid:18476853 http://dx.doi.org/10.1111/j.1440-1800.2008.00401.x 
[2] Wright LM, Leahey M.Nurses and families: A guide to family assessment and intervention. Fifth Rev Ed. Philadelphia: F.A. Davis, 2009.

[3] Harmon Hanson S, Gedaly-Duff V, Rowe Kaakinen J. Family Health Care Nursing: Theory, Practice \& Research. Third Ed. Philadelphia: F.A. Davis, 2005.

[4] Flanagan J. Clinically effective cancer care: working with families. Eur J Oncol Nurs. 2001; 5: 174-179. PMid:12849030 http://dx.doi.org/10.1054/ejon.2001.0132

[5] Östlund U. Family nursing in oncology care--do we need a paradigm shift? Eur J Oncol Nurs. 2010; 14: 181-182. PMid:20399142 http://dx.doi.org/10.1016/j.ejon.2010.03.003

[6] Saveman BI, Benzein E. Here comes the Swedes! A report on the dramatic and rapid evolution of family-focused nursing in Sweden. J Fam Nurs. 2001; 7: 303-310. http://dx.doi.org/10.1177/107484070100700308

[7] Wright L, Leahey M. Nurses and families - A Guide to Family Assessment and Intervention. Fourth Ed. Philadelphia: F.A. Davis, 2005.

[8] Benzein EG, Saveman BI. Health-promoting conversations about hope and suffering with couples in palliative care. Int J Palliat Nurs. 2008; 14: 439-445.

[9] Bell JM, Moules NJ, Wright LM. Therapeutic letters and the family nursing unit: a legacy of advanced nursing practice. J Fam Nurs. 2009; 15: 6-30. PMid:19218466 http://dx.doi.org/10.1177/1074840709331865

[10] Saveman BI. Family nursing research for practice: the Swedish perspective. J Fam Nurs. 2010; 16: 26-44. PMid:20145285 http://dx.doi.org/10.1177/1074840709360314

[11] Stensaker B, Maassen P, Borgan M, Oftebro M, Karseth B. Use, updating and integration of ICT in higher education: Linking purpose, people and pedagogy. Higher Education. 2007; 54: 417-433. http://dx.doi.org/10.1007/s10734-006-9004-x

[12] Allen E, Seaman J. Going the Distance: Online Education in the United States. 2011.tinyurl.com/cs4ogcw.

[13] Bentley GW, Cook PP, Davis K, Murphy M, Berding CB. RN to BSN program: transition from traditional to online delivery. Nurse Educator. 2003; 28: 121-126. PMid:12792275 http://dx.doi.org/10.1097/00006223-200305000-00005

[14] Bell JM. Family nursing education: faster, higher, stronger. J Fam Nurs. 2010; 16: 135-145. PMid:20406998 http://dx.doi.org/10.1177/1074840710368936

[15] Lee AC, Leung SO, Lingchan PS, Chung JO. Perceived level of knowledge and difficulty in applying family assessment among senior undergraduate nursing students. J Fam Nurs. 2010; 16: 177-95. PMid:20407000 http://dx.doi.org/10.1177/1074840710366566

[16] Anderson KH, Friedemann ML. Strategies to teach family assessment and intervention through an online international curriculum. J Fam Nurs. 2010; 16: 213-233. PMid:20407002 http://dx.doi.org/10.1177/1074840710367639

[17] Falloon G. Making the Connection: Moore's Theory of Transactional Distance and Its Relevance to the Use of a Virtual Classroom in Postgraduate Online Teacher Education. Journal of Research on Technology in Education. 2011; 4: 187-209.

[18] Umeå University. Information about Cambro [Internet]. 2010. Available from: http://www.it.umu.se/english/our-services/cambro/more-cambro-information/.

[19] SAKAI. A community of educators collaborating to create open software that advances teaching, learning and research [Internet]. 2012. Available from: http://sakaiproject.org/.

[20] Adobe. Adobe Connect [Internet]. 2012. Available from: http://www.adobe.com/products/adobeconnect.html.

[21] Baghcheghi N, KoohestaniHR, Rezaei K. A comparison of the cooperative learning and traditional learning methods in theory classes on nursing students' communication skill with patients at clinical settings. Nurse Educ Today. 2011; 31: 877-882. PMid:21288608 http://dx.doi.org/10.1016/j.nedt.2011.01.006

[22] Wright LM, Bell JM. Beliefs and illness: A model for healing. Canada: 4th Floor Press, 2009.

[23] Polit DF, Beck CT. Nursing research: Generating and assessing evidence for nursing practice. Eight Ed. Philadelphia: Lippincott Williams \& Wilkins, 2008.

[24] Boyatzis, R.E., Transforming Qualitative Information: Thematic Analysis and Code Development. New York: Sage, 1998.

[25] Benzein E, Johansson P, Årestedt KF, Berg A, Saveman BI. Families' Importance in Nursing Care: Nurses' Attitudes--an instrument development. J Fam Nurs. 2008; 14: 97-117. PMid:18281645 http://dx.doi.org/10.1177/1074840707312716

[26] Saveman BI, Benzein EG, Engström AH, Årestedt K. Refinement and psychometric reevaluation of the instrument: Families' Importance In Nursing Care-Nurses' Attitudes. J Fam Nurs. 2011; 17: 312-329. PMid:21813813 http://dx.doi.org/10.1177/1074840711415074

[27] SPSS 18.0 for Windows. Chicago: SPSSinc, 2009.

[28] Moules NJ, Bell JM, Paton BI, Morck AC. Examining pedagogical practices in family systems nursing: intentionality, complexity, and doing well by families. J Fam Nurs. 2012; 18: 261-295. PMid:22274936 http://dx.doi.org/10.1177/1074840711435508 
[29] Gaudine AP, Moralejo DG. What can faculty members and programs do to improve students' learning? ISRN Nurs. 2011; 2011: 649431.

[30] Woltering V, Herrler A, Spitzer K, Spreckelsen C. Blended learning positively affects students' satisfaction and the role of the tutor in the problem-based learning process: results of a mixed-method evaluation. Adv Health Sci Educ Theory Pract. 2009; 14: 725-738. PMid:19184497 http://dx.doi.org/10.1007/s10459-009-9154-6

[31] Benzein E, Johansson P, Årestedt KF, Saveman BI. Nurses' attitudes about the importance of families in nursing care: a survey of Swedish nurses. J Fam Nurs. 2008; 14: 162-180. PMid:18480033 http://dx.doi.org/10.1177/1074840708317058

[32] Kazdin AE. Research design in clinical psychology. Fourth Ed. Boston: Allyn and Bacon 2003.

[33] Ekman I, Swedberg K, Taft C, Lindseth A, Norberg A, Brink E, et al. Person-centered care--ready for prime time. Eur J Cardiovasc Nurs. 2011; 10: 248-251. PMid:21764386 http://dx.doi.org/10.1016/j.ejcnurse.2011.06.008

[34] Svavarsdottir EK. Excellence in nursing: a model for implementing Family Systems Nursing in nursing practice at an institutional level in Iceland. J Fam Nurs. 2008; 14: 456-468. PMid:19139159 http://dx.doi.org/10.1177/1074840708328123

[35] Leahey M, Svavarsdottir EK. Implementing family nursing: how do we translate knowledge into clinical practice? J Fam Nurs. 2009; 15: 445-460. PMid:19783792 http://dx.doi.org/10.1177/1074840709349070

[36] Somekh B. Factors affecting teachers' pedagogical adoption of ICT. In International handbook of informational technology in primary and secondary education. J. Voogt and G. Knezek, eds. New York: Springer. 2008; 449-460. http://dx.doi.org/10.1007/978-0-387-73315-9_27

[37] Laurillard D. Technology Enhanced Learning as a Tool for Pedagogical Innovation. Journal of Philosophy of Education. 2008; 42(3/4): 521-533. http://dx.doi.org/10.1111/j.1467-9752.2008.00658.x

[38] Wear D, Zarconi J, Garden R, Jones T. Reflection in/and Writing: Pedagogy and Practice in Medical Education. Acad Med. 2012; 87: 603-609. PMid:22450174 http://dx.doi.org/10.1097/ACM.0b013e31824d22e9

[39] Laurillard D. Rethinking university teachning, a framework for effective use of learning technologies. Second Ed. London: Routledge Falmer, 2002. http://dx.doi.org/10.4324/9780203304846

[40] Tomm K. Interventive interviewing: Part II. Reflexive questioning as a means to enable self-healing. Fam Process. 1987; 26: 167-183. PMid:3595824 http://dx.doi.org/10.1111/j.1545-5300.1987.00167.x

[41] Tomm K. Interventive interviewing: Part III. Intending to ask lineal, circular, strategic, or reflexive questions? Fam Process. 1988; 27: 1-15. PMid:3360095 http://dx.doi.org/10.1111/j.1545-5300.1988.00001.x

[42] Andersen T. Reflecting processes: Acts of forming and informing. In The reflecting team in action. S. Friedman, ed. Guilford: New York, 1995, 11-37.

[43] Moules NJ. Therapeutic letters in nursing: examining the character and influence of the written word in clinical work with families experiencing illness. J Fam Nurs. 2009; 15: 31-49. PMid:19211546 http://dx.doi.org/10.1177/1074840709331639

[44] Brown J. Circular questioning: An introductory guide. Australian and New Zealand Journal of Family Therapy. 1997; 18: 109-114.

[45] Duhamel F. Implementing family nursing: how do we translate knowledge into clinical practice? Part II: The evolution of 20 years of teaching, research, and practice to a Center of Excellence in Family Nursing. J Fam Nurs. 2010; 16: 8-25. PMid:20145284 http://dx.doi.org/10.1177/1074840709360208

[46] Ekeland AG, Bowes A, Flottorp S. Effectiveness of telemedicine: a systematic review of reviews. Int J Med Inform. 2010; 79: 736-771. PMid:20884286 http://dx.doi.org/10.1016/j.ijmedinf.2010.08.006

[47] Barak A, Klein B, Proudfoot JG. Defining internet-supported therapeutic interventions. Ann Behav Med. 2009 ; 38: 4-17. PMid:19787305 http://dx.doi.org/10.1007/s12160-009-9130-7 